\section{Mars 2014}

Le mois de mars, printanier sur l'ensemble du pays, a été particulièrement doux, sec et ensoleillé sur la moitié nord de la France.

Les températures ont été supérieures à la normale sur la quasi-totalité du pays, souvent de plus de $2^{\circ} \mathrm{C}$ dans le Nord-Est où les maximales ont été particulièrement élevées. Moyennée sur la France, la température mensuelle est supérieure de $1,1^{\circ} \mathrm{C}$ à la normale.

Les précipitations ont été déficitaires sur une grande partie du pays excepté au sud de la Garonne, sur la Côte d'Azur et en Corse. Le déficit est supérieur à $70 \%$ de I'Île-de-France au Nord-Est. En moyenne sur la France, la pluviométrie a été inférieure à la normale de près de $35 \%$.

Le vent a été généralement peu fréquent. Le Sud-Ouest a connu deux épisodes de vent fort, en début de mois avec la tempête Christine, puis en fin de mois dans le domaine de l'autan.

L'ensoleillement a été généreux sur l'ensemble du pays. Avec un excédent supérieur à $60 \%$ de l'Anjou à la frontière belge ainsi qu'en Alsace et en Lorraine, des records mensuels ont été battus.

Météo-France DClim
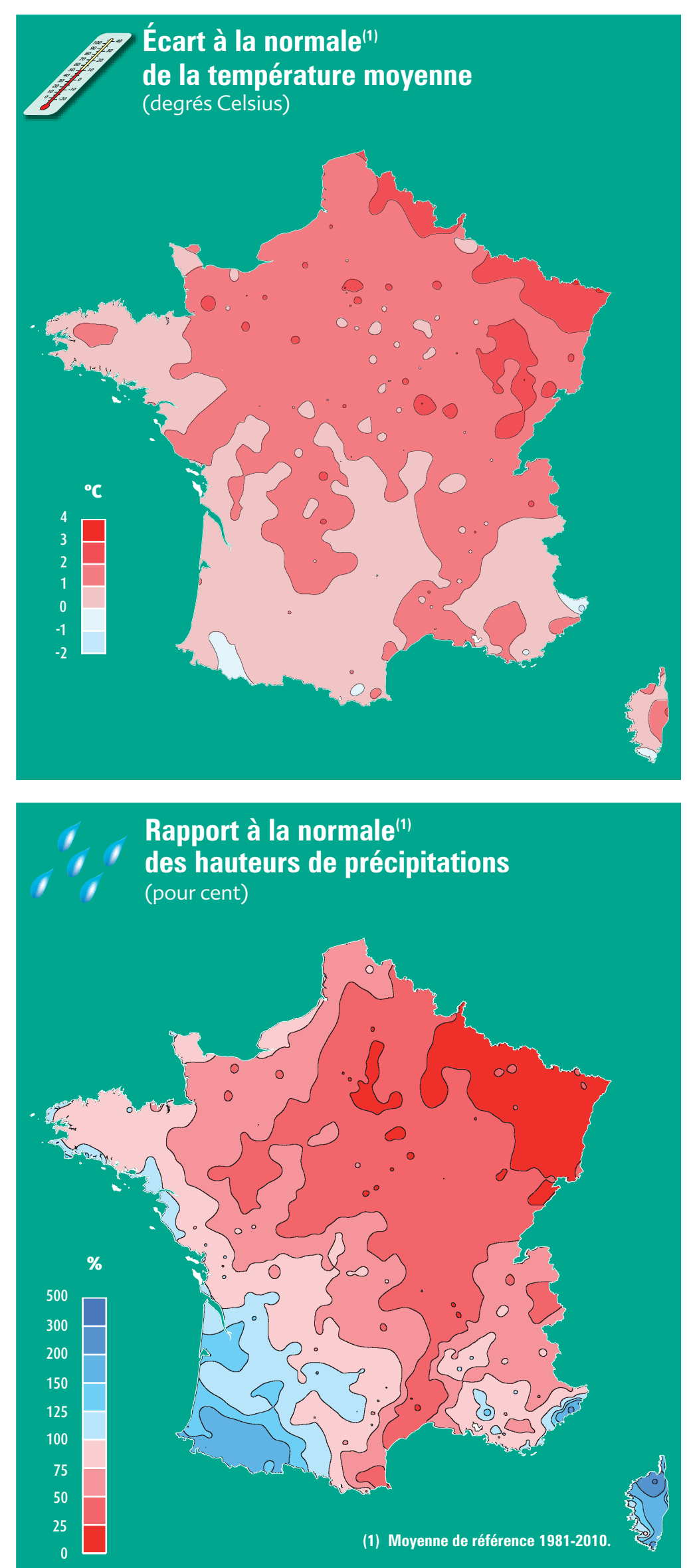


\section{Mars 2014}
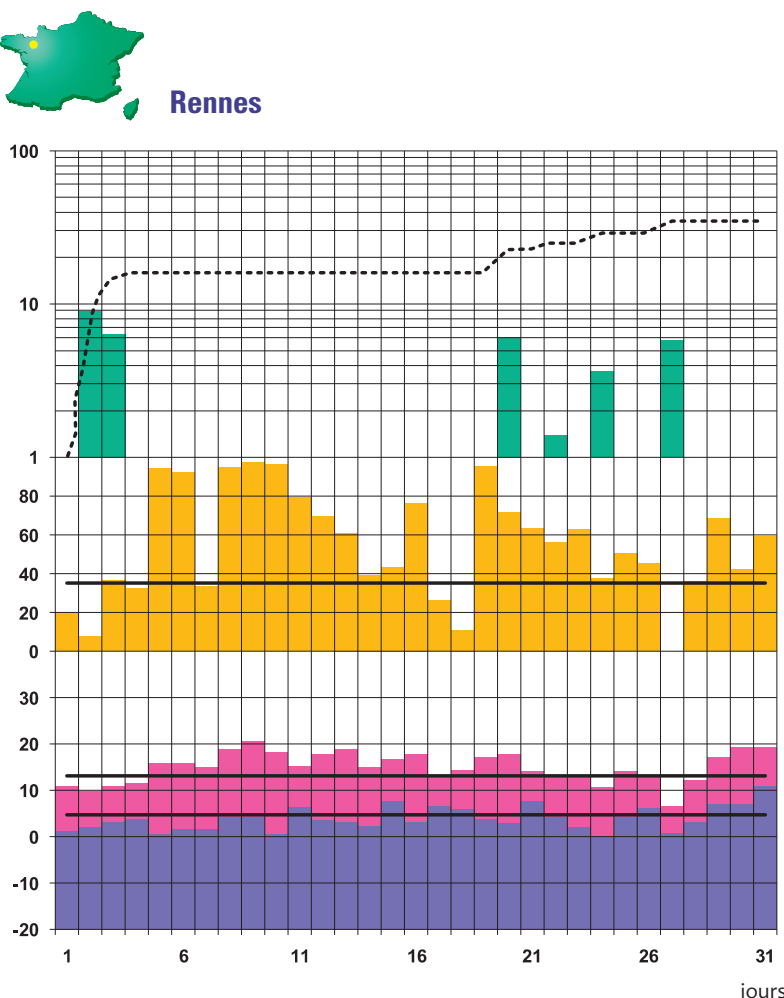

Total mensuel des précipitations : $60 \%$ de la normale

Fraction d'insolation moyenne : excédentaire

Température moyenne : $>0,6^{\circ} \mathrm{C}$ à la normale

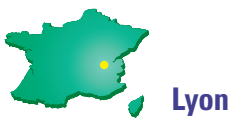

100

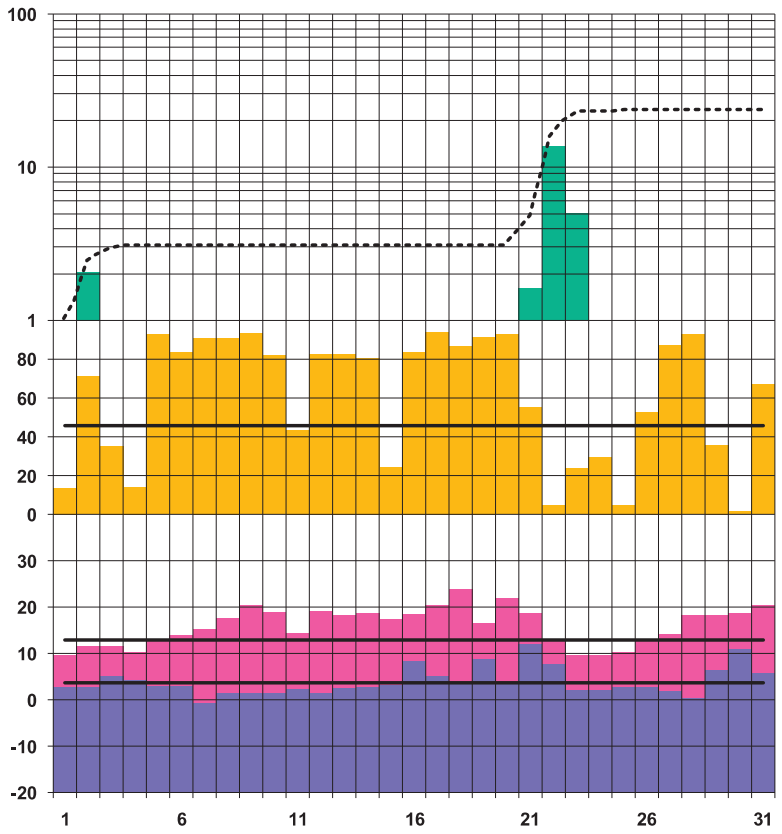

Total mensuel des précipitations : $50 \%$ de la normale

Fraction d'insolation moyenne : excédentaire

Température moyenne : $>1,7^{\circ} \mathrm{C}$ à la normale

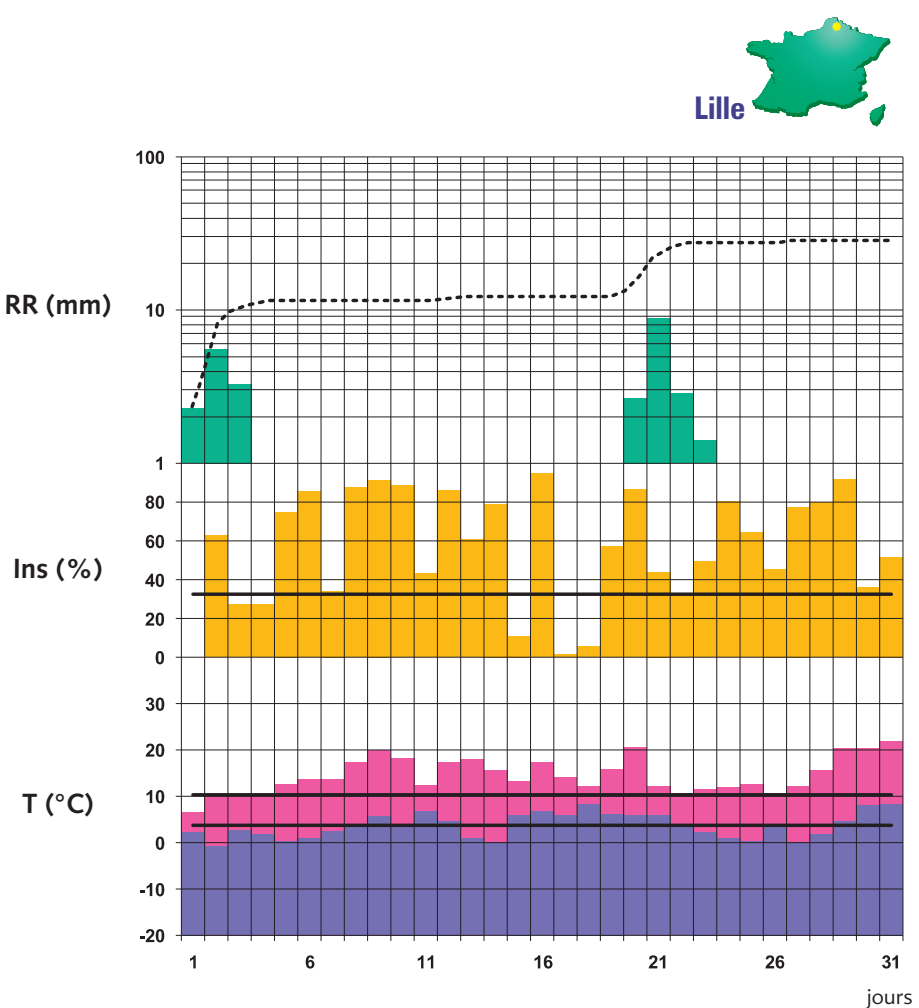

Total mensuel des précipitations : $50 \%$ de la normale

Fraction d'insolation moyenne : excédentaire

Température moyenne : $>2,0^{\circ} \mathrm{C}$ à la normale
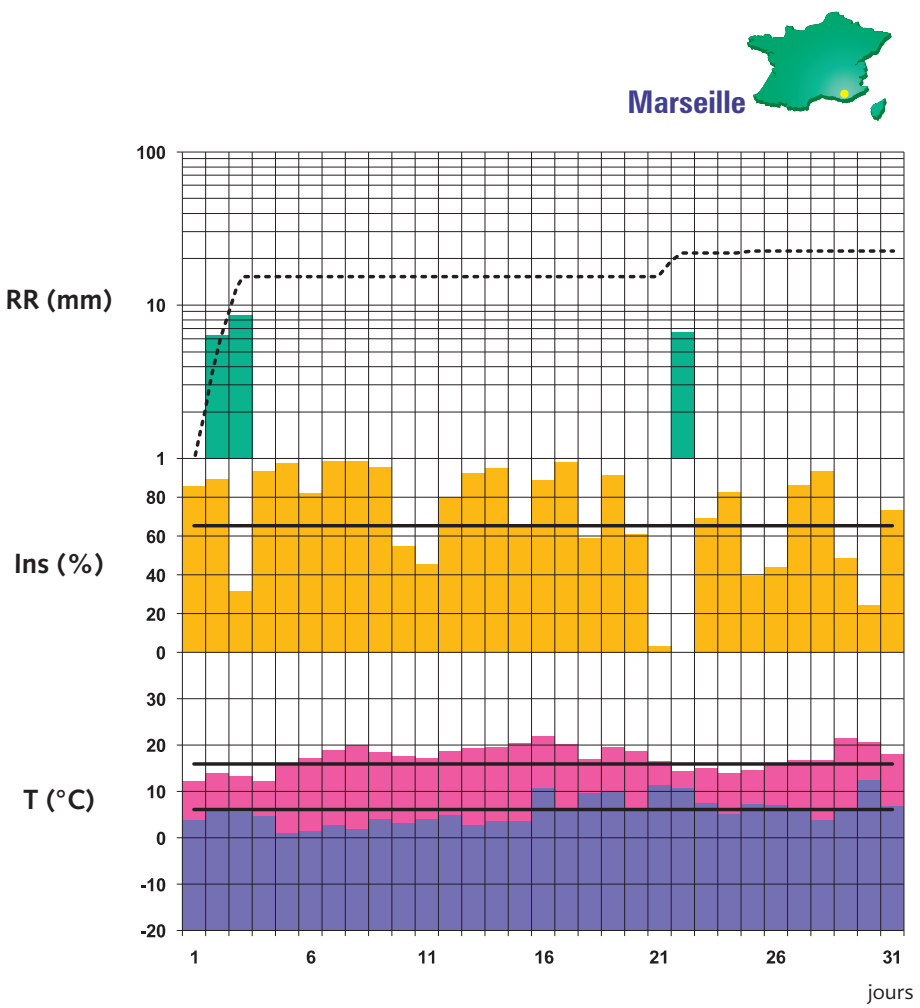

Total mensuel des précipitations : $70 \%$ de la normale

Fraction d'insolation moyenne : normale

Température moyenne : $>0,8^{\circ} \mathrm{C}$ à la normale

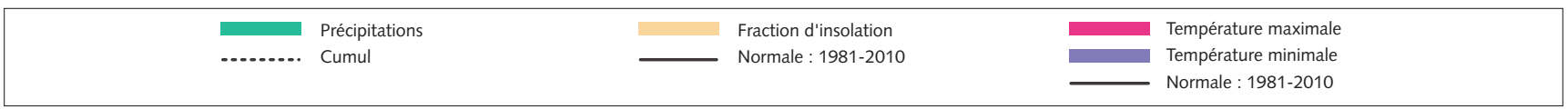




\section{Mars 2014}
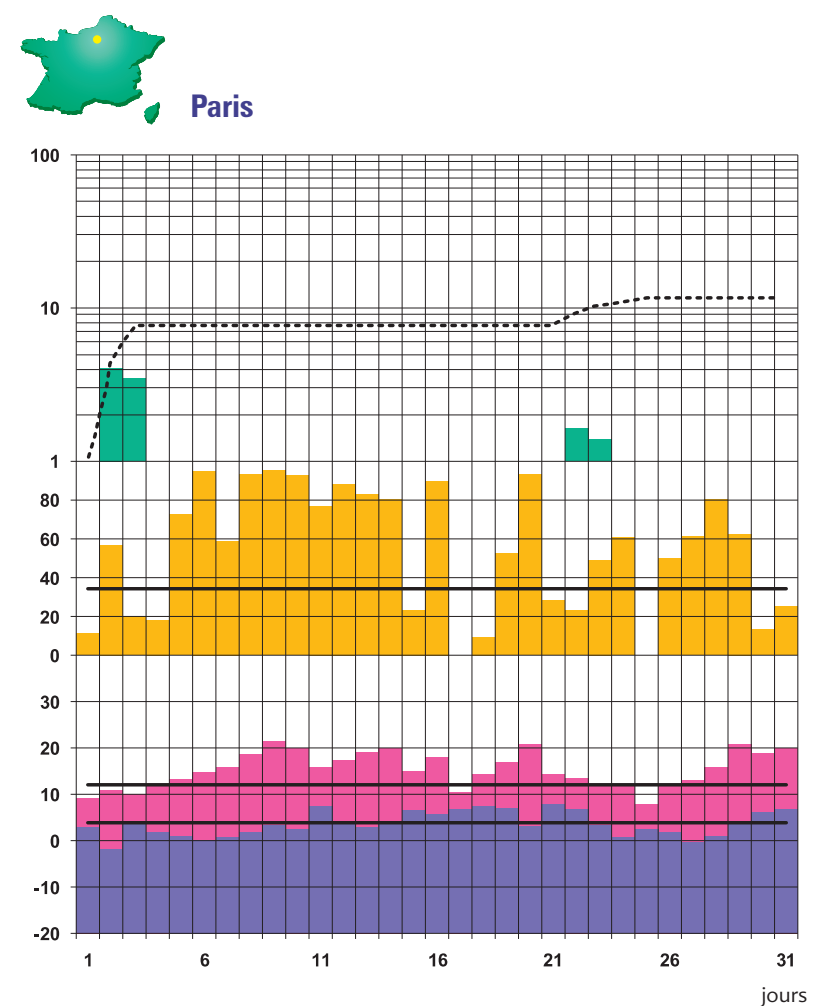

Total mensuel des précipitations : $20 \%$ de la normale

Fraction d'insolation moyenne : excédentaire

Température moyenne : > 1,6 ${ }^{\circ} \mathrm{C}$ à la normale
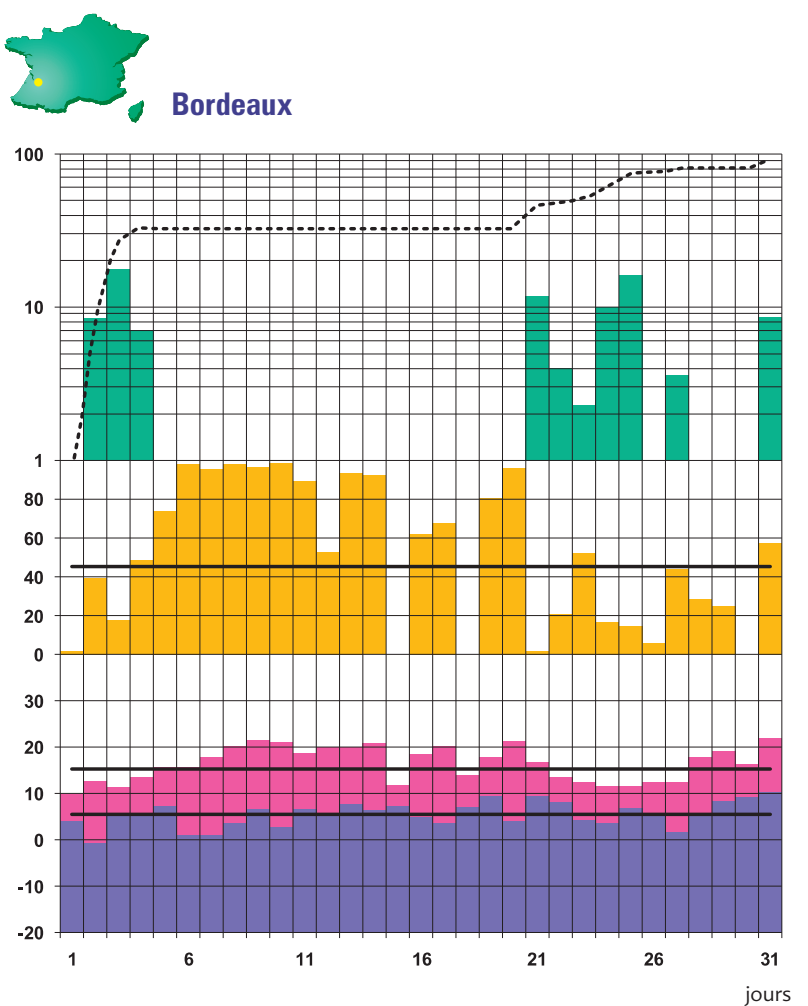

Total mensuel des précipitations : 1,3 fois la normale

Fraction d'insolation moyenne : normale

Température moyenne : $>0,7^{\circ} \mathrm{C}$ à la normale

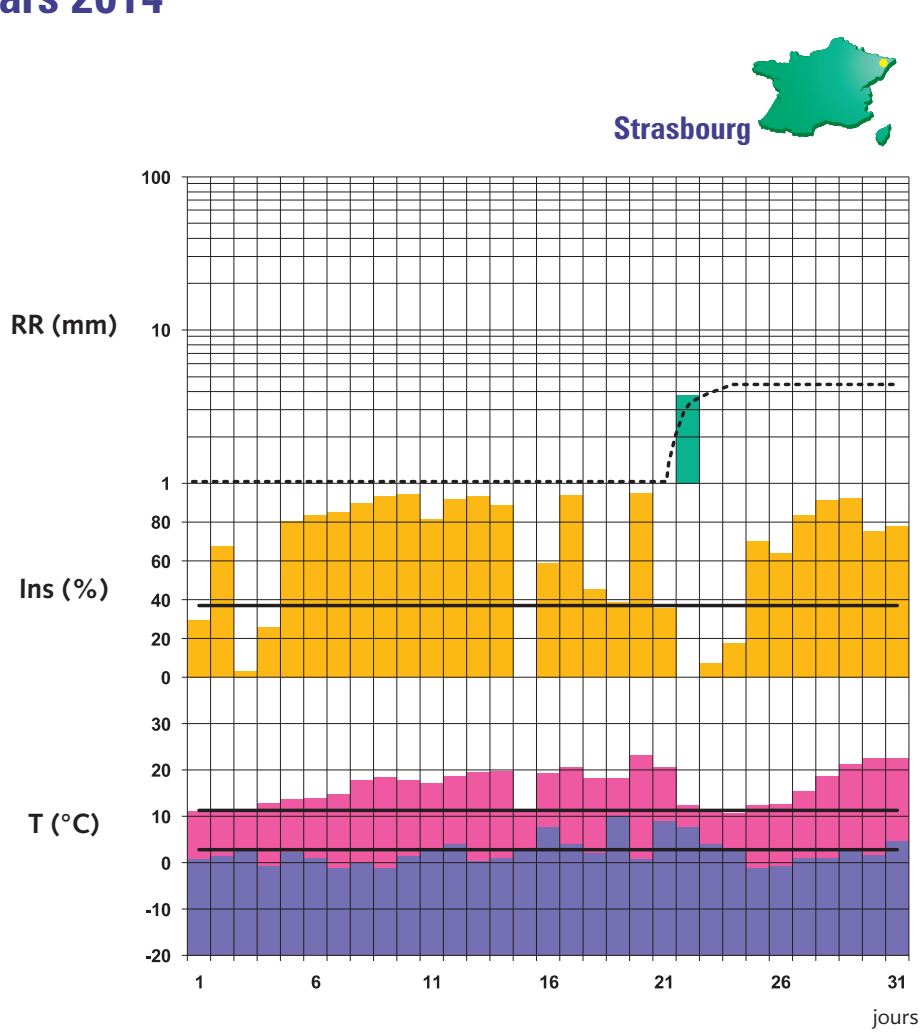

Total mensuel des précipitations : $10 \%$ de la normale

Fraction d'insolation moyenne : excédentaire

Température moyenne : > 2,3 ${ }^{\circ} \mathrm{C}$ à la normale

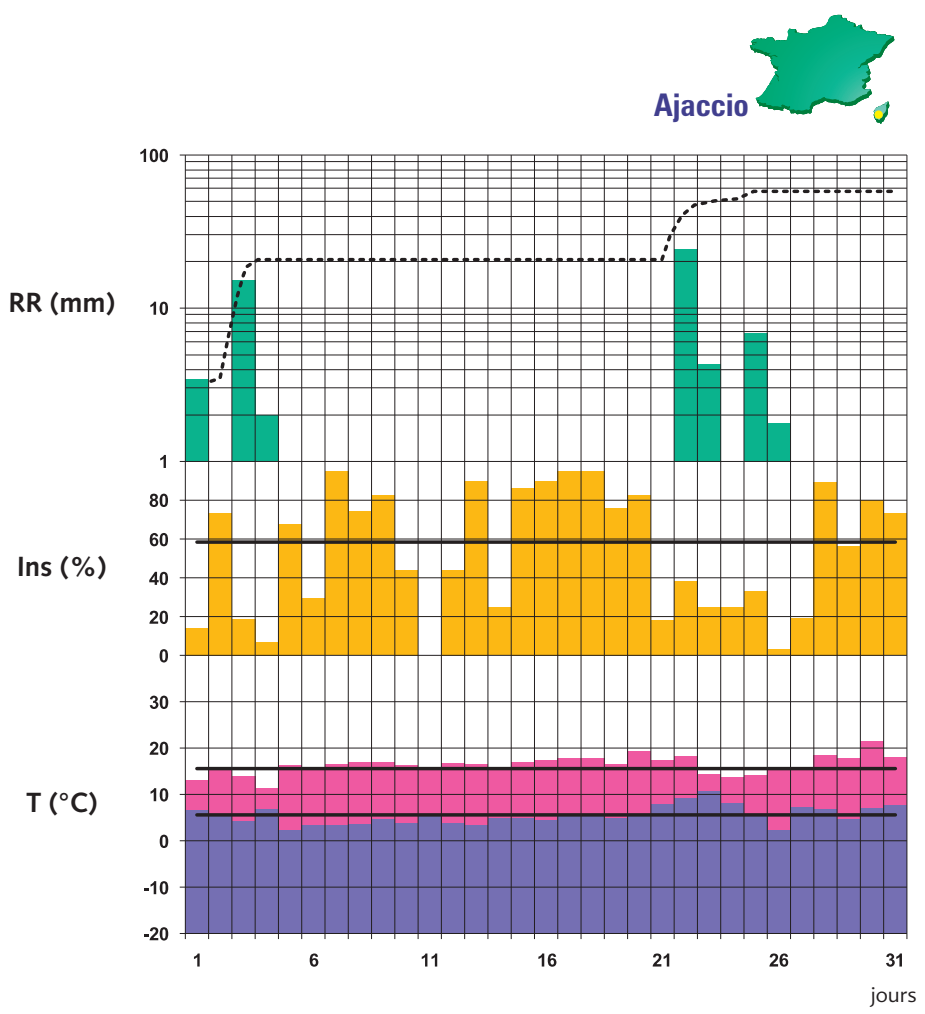

Total mensuel des précipitations : 1,2 fois la normale

Fraction d'insolation moyenne : normale

Température moyenne : $>0,3{ }^{\circ} \mathrm{C}$ à la normale

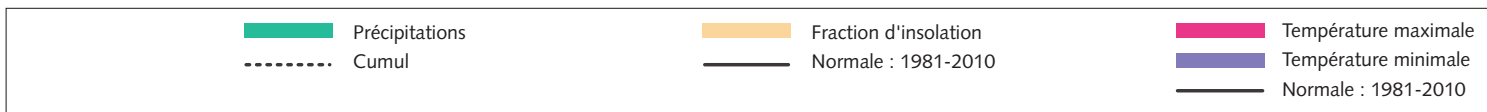

